\section{(A) Check for updates}

Cite this: Nanoscale, 2020, 12, 7109

\title{
Photoacoustic identification of laser-induced microbubbles as light scattering centers for optical limiting in a liquid suspension of graphene nanosheets $\uparrow$
}

\author{
Qiuhui Zhang, (D) tab $^{\mathrm{a}}$ Yi Qiu, (D) f $^{\mathrm{b}, \mathrm{c}}$ Feng Lin, (D) ${ }^{\mathrm{b}, \mathrm{d}}$ Chao Niu, (D) ${ }^{\mathrm{e}}$ Xufeng Zhou, (D) ${ }^{\mathrm{f}}$ \\ Zhaoping Liu, (D) ${ }^{f}$ Md Kamrul Alam, ${ }^{g}$ Shenyu Dai, (D) ${ }^{\text {b, h }}$ Wei Zhang, (D) \\ Jonathan $\mathrm{Hu},(\mathbb{D})^{\mathrm{e}}$ Zhiming Wang ${ }^{\mathrm{d}}$ and Jiming Bao (D)*d,g
}

\begin{abstract}
Liquid suspensions of carbon nanotubes, graphene and transition metal dichalcogenides have exhibited excellent performance in optical limiting. However, the underlying mechanism has remained elusive and is generally ascribed to their superior nonlinear optical properties such as nonlinear absorption or nonlinear scattering. Using graphene as an example, we show that photo-thermal microbubbles are responsible for optical limiting as strong light scattering centers: graphene sheets absorb incident light and become heated up above the boiling point of water, resulting in vapor and microbubble generation. This conclusion is based on the direct observation of bubbles above the laser beam as well as a strong correlation between laser-induced ultrasound and optical limiting. In situ Raman scattering of graphene further confirms that the temperature of graphene under laser pulses rises above the boiling point of water but still remains too low to vaporize graphene and create graphene plasma bubbles. Photo-thermal bubble scattering is not a nonlinear optical process and requires very low laser intensity. This understanding helps us to design more efficient optical limiting materials and understand the intrinsic nonlinear optical properties of nanomaterials.
\end{abstract}

Received 12th December 2019, Accepted 20th February 2020

DOI: 10.1039/c9nr10516f

rsc.li/nanoscale
OL has attracted a lot of attention since the invention of the laser. ${ }^{1}$ However, it has been challenging to identify or develop suitable materials to exhibit OL at a controlled threshold of laser intensity. ${ }^{1-6}$ Due to the same reason, the mechanism of OL has also remained an active research field. OL is generally regarded as a nonlinear optical phenomenon because it can be induced by nonlinear absorption or scattering. ${ }^{1-6}$ Recently, atomically thin 2D nanomaterials have emerged as novel optoelectronic materials with strong nonlinear optical properties. $^{7-11}$ As an important application, OL has been reported in liquid suspensions of graphene, ${ }^{3,5,12-20}$ graphene oxide (GO), ${ }^{3,19,21-30}$ transition metal dichalcogenides (TMD), ${ }^{4,31-37}$ and black phosphorus. ${ }^{2,38-41}$ Some OL were observed even with CW lasers..$^{29,30,42,43}$

However, as in previous OL materials, the mechanism of OL in these $2 \mathrm{D}$ nanomaterials has not been clearly identified, and more importantly, many proposed mechanisms are either confusing or misleading as to whether the OL is originating from the intrinsic nonlinear optical properties of nanomaterials. ${ }^{12-14,17,18,21-23,31-33,35,38,44-51}$ Based on the observed strong scattered light, the majority of reported works attribute OL to nonlinear scattering. . $^{1,3,12-14,17,33,38,44,46-50}$ Bubbles were suggested as possible nonlinear scattering 
centers, but there is no direct experimental proof, and it was still not clear whether the bubbles were generated by plasma breakdown of nanomaterials ${ }^{14,49,50}$ or evaporation of solvents. ${ }^{3,13,14,17,31-33,38,44,46,48,49}$ A serious confusion arises when many people still associate OL with the nonlinear optical properties of nanomaterials by simply referring it as nonlinear scattering despite the proposed bubble scattering mechanism. ${ }^{12-14,17,33,38,44,46,48}$ To make the situation worse, the nonlinear optical coefficient $\chi^{3}$ of nanostructures was also calculated from $Z$-scan measurement before identifying the $\mathrm{OL}$ mechanism, ${ }^{3,12-14,17,18,22,23,29,33,38,45,48-50,52,53}$ because if the scattering comes from bubbles, it has nothing to do with $\chi^{3}$.

In this work, we chose graphene as a representative nanomaterial to investigate the mechanism of OL..$^{2-5,12-15,17,18,23,31}$ Using direct imaging of bubbles and the correlation between photoacoustic signals and OL, we conclude that laser-induced microbubbles are responsible for the sudden drop in optical transmission. We also point out that this is the most effective method to achieve OL at low laser intensity, and bubbleinduced OL cannot be regarded as nonlinear scattering because it is not directly related to the nonlinear optical property of nanomaterials. This conclusion is applicable to other low dimensional materials. The understanding and clarification of the OL mechanism helps to design a more efficient optical limiter and explore the intrinsic nonlinear optical properties of nanomaterials.

\section{Results and discussion}

Graphene nanosheets were synthesized via electrochemical exfoliation of highly oriented pyrolytic graphite (HOPG) in $\mathrm{K}_{2} \mathrm{SO}_{4}$ salt solution. ${ }^{54}$ After filtration and ultra-sonication in NMP for 2 hours, the average size of graphene was $1.5 \mu \mathrm{m}$ with a thickness of $2.4 \mathrm{~nm} .^{55,56}$ Fig. 1a shows our initial experimental setup to investigate the mechanism of OL. In addition to the traditional open-aperture $Z$-scan configuration, we used a high-speed video camera coupled with a microscope objective lens. This setup can not only monitor the scattered light like a photodetector used in previous $Z$-scan experiments, ${ }^{12,13,17,33,38,46}$ but also directly image the motion of graphene sheets and emerging bubbles. Here, a $527 \mathrm{~nm}$ pulsed laser (150 ns pulse width, $1 \mathrm{kHz}$ repetition rate) was focused with a $10 \mathrm{~cm}$ focal length lens on a cuvette, which was filled with graphene suspension in deionized water (DIW). Fig. 1b shows normalized $Z$-scan transmission at increasing laser power. OL can be clearly confirmed by the sudden drop in transmission near the focus point of the laser beam. As usual, a stronger OL, i.e., lower optical transmission, is achieved with an increasing laser power.

The stronger scattering from the focused laser spot is obvious from Fig. 1c. To find out whether the strong scattering originated from bubbles, we zoomed in the camera to obtain higher resolution pictures (Fig. 1d and e). Bubble-like ring objects could be seen in Fig. 1d. However, we quickly realized that these were not bubbles, they were the same bright spots
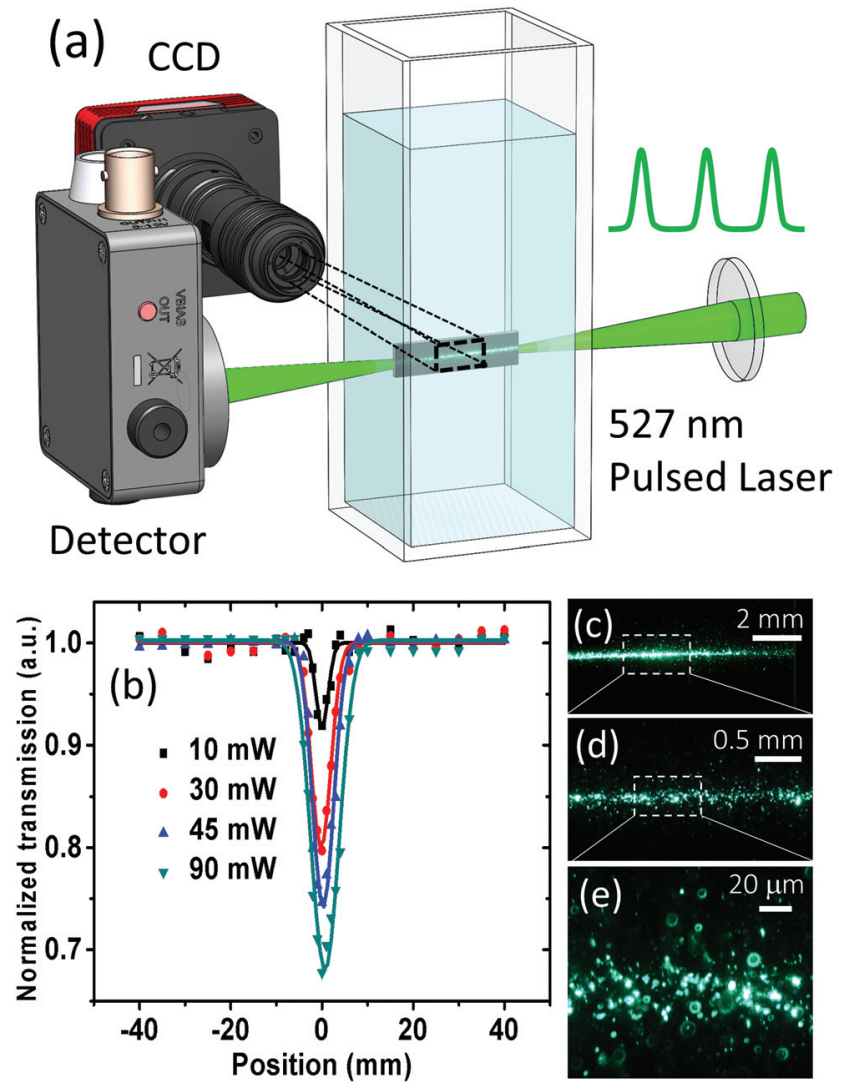

Fig. 1 Open-aperture optical limiting Z-scan experiment with direct imaging of light scattering centers. (a) Schematic for the experimental setup. (b) Z-Scan curves of graphene suspension with different laser powers. (c-e) Optical images of scattering centers with increasing magnifications. The linear transmission of graphene suspension is $60 \%$.

as in low resolution, appearing as bubbles when bright spots were out of focus. Because the lateral sizes of graphene sheets are typically in the range of $500 \mathrm{~nm}$ to a few micrometers, larger than the wavelength of visible light, graphene sheets can scatter light and appear as bright spots. In other words, both graphene and bubbles can scatter light, and it is difficult to distinguish them with this direct optical imaging.

To distinguish graphene scattering from potential bubble scattering and to obtain a clear image of bubbles, we designed a new configuration. As shown in Fig. 2a, we focused two perpendicular $633 \mathrm{~nm}$ laser beams with two cylindrical lenses to create a light sheet above the $527 \mathrm{~nm}$ laser beam, and monitored the area for a possible bubble in this thin region. ${ }^{57,58} \mathrm{~A}$ $527 \mathrm{~nm}$ longpass filter was placed in front of the camera to block the strong green laser light. There are several reasons for this detection configuration. First, a thin light sheet allowed us to detect bubbles only in the light sheet and made bubbles outside the light sheet invisible so that ring-like bubble artifacts can be avoided. ${ }^{57-59}$ Second, the sheet provided a large space for us to study the dynamics of possible bubbles. Third, we expected to observe larger size bubbles as microbubbles merged when drifting upward due to the buoyant force. The rationale behind this configuration is that if there were no 



Fig. 2 Experimental setup to observe and identify photothermal bubbles above the laser beam. (a) Experimental setup. A light sheet is created above the laser beam with a $633 \mathrm{~nm}$ laser. (b, c) Identification of bubbles from their shapes, large sizes and faster speeds moving to the water surface.

micro-bubbles generated in the laser beam, we should not observe any bubbles above the beam.

As expected, fewer scattering centers were observed due to the thin light sheet. Fig. $2 \mathrm{~b}$ and $\mathrm{c}$ show two consecutive snapshots separated by $200 \mathrm{~ms}$. No ring-shaped scattering centers were observed, confirming that they were caused by out-offocus of the camera. Now there were two types of scattering centers: large-sized centers with two or three bright points together such as $\mathrm{A}$ and $\mathrm{C}$ versus an individual, dimmer point such as B. A and C were bubbles with a diameter of $30 \mu \mathrm{m}$, their two left and right bright spots were due to the scattering of $633 \mathrm{~nm}$ laser in the horizontal directions, while a relatively weak point was due to the scattering of light in the vertical direction. The scattering by a single graphene sheet produced a single isolated spot, such as point B. This identification of bubbles from graphene sheets can be further confirmed by their higher upward moving speed: bubble A moved up by
$351 \mu \mathrm{m}$ while graphene B only traveled $261 \mu \mathrm{m}$ in 0.2 seconds. This is because the motion of graphene sheet was driven by the fluid convection, which was induced by local laser heating. Bubbles moved faster because of the additional buoyant force. Note that bubbles were only observed above the focused laser beam when OL occurred. These observations indicate that microbubbles must be produced in the laser beam during the OL.

Having observed the bubbles during OL, we employed a new technique to further confirm the generation of microbubbles and identify them as light scattering centers. Fig. 3a shows the new experimental design where a hydrophone was used to detect ultrasound..$^{57,58}$ The purpose was to hear laserinduced micro-bubbles instead of seeing them. To establish a tight correlation between ultrasound generation and OL, we performed OL first, obtained the $Z$-scan curve shown in Fig. 3b, and then chose three positions A, B, and C. Position A exhibited the strongest $\mathrm{OL}$, while position $\mathrm{C}$ exhibited no OL. Fig. 3c shows the corresponding ultrasound traces. It can be seen that the strongest ultrasound was observed at position A, and the ultrasound was too weak to be detected at position C. We want to point out that under nanosecond laser excitation, graphene can produce ultrasound through thermal

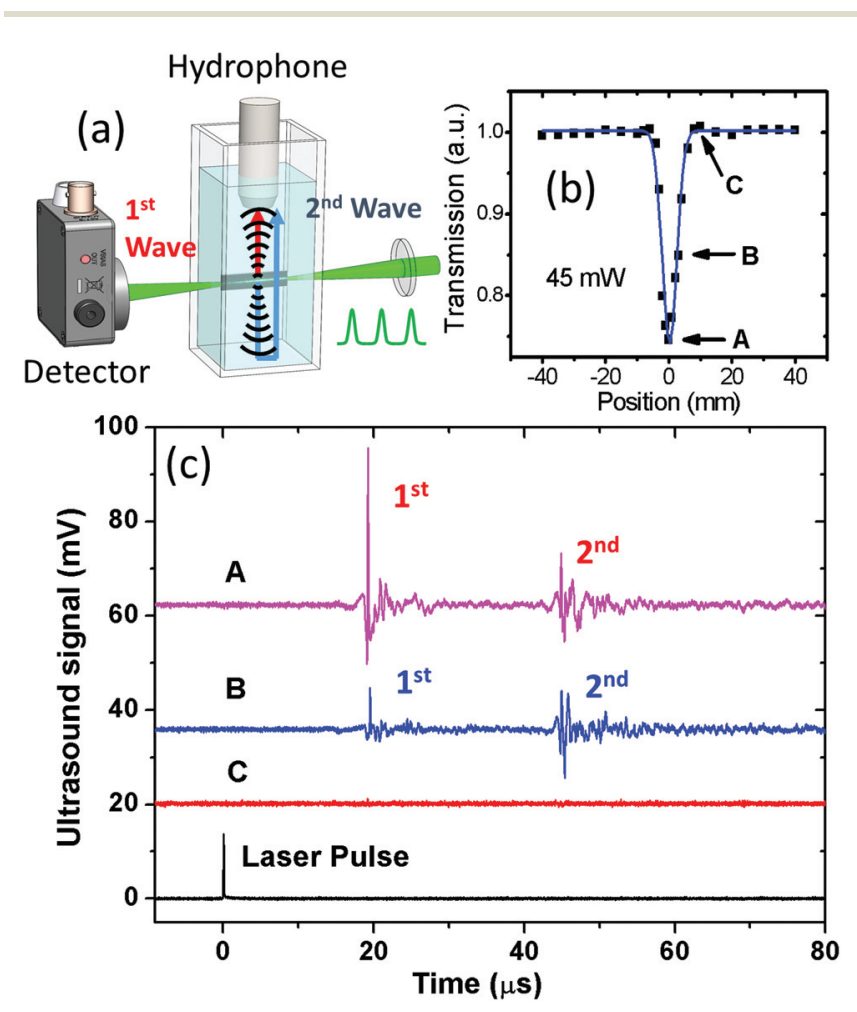

Fig. 3 Experimental setup to correlate OL with the photoacoustic signal of bubbles. (a) Schematic of the experimental setup. (b) The same $Z$-scan curve of graphene suspension as in Fig. 1 b under a $45 \mathrm{~mW}$ laser. (c) Ultrasound signals at different positions of the OL Z-scan curve. The second ultrasound pulses around $45 \mu$ s were due to reflection from the bottom of the cuvette. The laser pulse is also included to mark the beginning of laser excitation. The $2^{\text {nd }}$ pulse $\left(2^{\text {nd }}\right.$ Wave) is a reflection of the $1^{\text {st }}$ pulse $\left(1^{\text {st }}\right.$ Wave) from the bottom of the cuvette. 
expansion at position $\mathrm{C}$, but that ultrasound signal will be dramatically enhanced with the microbubbles that were generated at position $\mathrm{A} .^{60-62}$

A pre-condition for bubble generation is that the temperature of graphene sheets must become higher than the boiling point of water under laser excitation. To estimate the rise of temperature due to laser absorption during OL, we used the same excitation laser to measure the Raman shift of graphene. Because of a relatively long interaction time ( $150 \mathrm{~ns})$, this Raman shift will reflect an average temperature of graphene during laser irradiation. Fig. 4a shows the Raman-OL experimental setup, and Fig. 4b shows the Raman spectra of graphene sheets under the same laser powers of 10 and $45 \mathrm{~mW}$ as shown in Fig. 1. A Raman shift of nearly $3 \mathrm{~cm}^{-1}$ was observed, corresponding to a rise of $180{ }^{\circ} \mathrm{C},{ }^{63}$ which brings the sheets above the boiling point of water. This proves that the temperature of graphene became high enough to generate vapor on its surface. However, this temperature rise was certainly not high enough to vaporize graphene and create a micro-plasma which could also become a light scattering center. ${ }^{64-66}$ Such a mechanism can be further ruled out since no blackbody radiation in the visible wavelength was observed.

Based on the above observations and discussions, we can now depict each step of OL. As shown in Fig. 5a, graphene sheets absorbed incident laser energy and became hot, vapor-
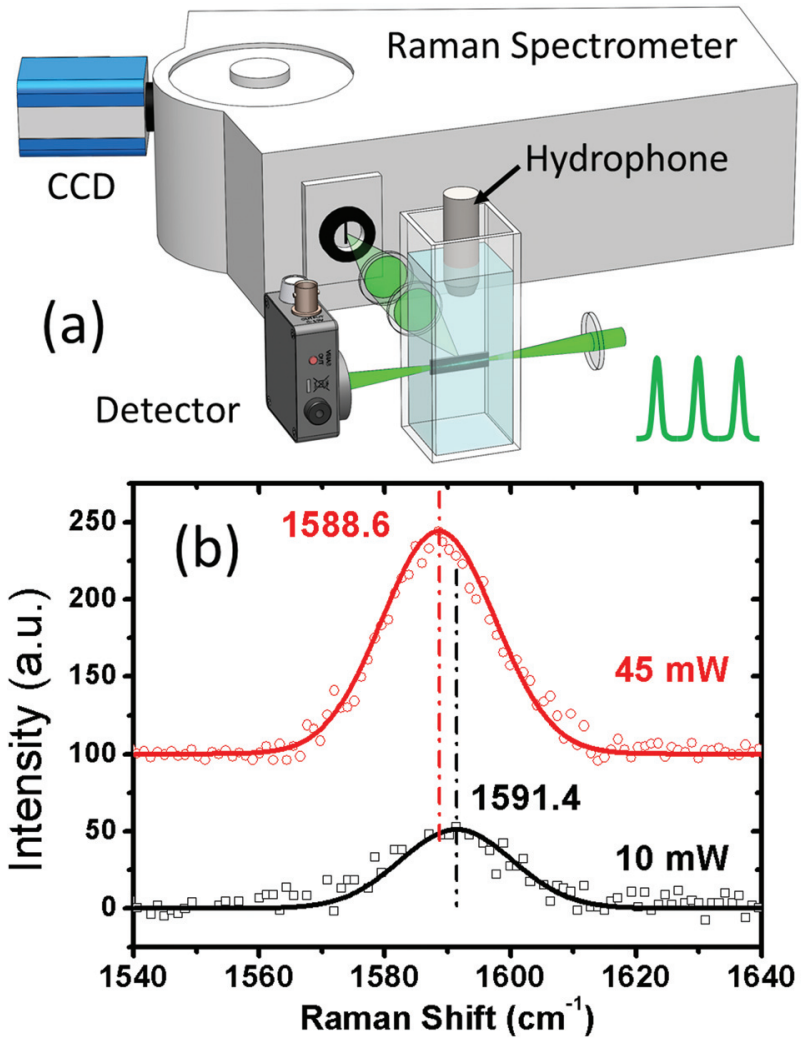

Fig. 4 Measurement of graphene temperature using Raman scattering. (a) Schematic for the experimental setup. (b) The Raman spectra of graphene under $10 \mathrm{~mW}$ and $45 \mathrm{~mW}$ of laser powers.
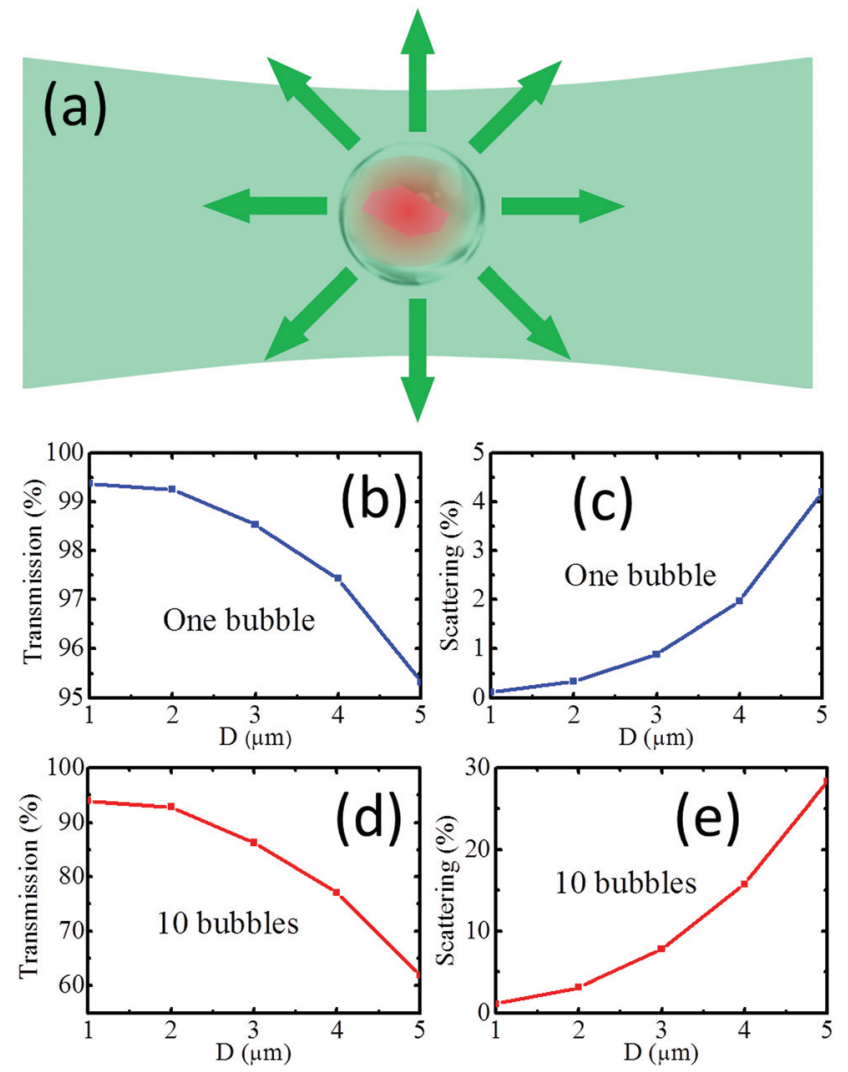

Fig. 5 Scattering of light by laser-induced bubbles. (a) Cartoon depicting laser heating of graphene flake creates a bubble scattering center. (b, d) Optical transmission induced by one (ten) bubble vs. the diameter of a bubble. (c, e) The scattering induced by one (ten) bubble vs. the diameter of a bubble.

izing the surrounding water and producing microbubbles, ${ }^{48,67-70}$ which in turn strongly scattered incident laser and reduced its transmission. Note that reaching the boiling point is only a necessary condition for OL, other solvent parameters such as thermal capacity and conductivity determine the temperature evolution of graphene flakes, ${ }^{13,71,72}$ and the dynamics of bubbles is mainly governed by the surface tension of solvents. ${ }^{13,48,67-70}$ Fig. S1 and $\mathrm{S} 2 \uparrow$ show that the boiling points of water and NMP can be quickly reached, and OL is stronger in NMP than in water although the boiling point of NMP $\left(202^{\circ} \mathrm{C}\right)$ is much higher than that of water.

Microbubbles were proposed as light scattering centers in OL, ${ }^{12-14,33,38,44,46,48}$ as a bubble can create a total reflection of light, but the scattering properties of bubbles and graphene sheets were not quantitatively investigated and compared. Here we use FDTD from Lumerical to calculate the transmission of light through a bubble, assuming that a $0.8 \mu \mathrm{m}$ diameter graphene sheet with a thickness of $5 \mathrm{~nm}$ is located in the center of the bubble with different sizes, as shown in Fig. 5a. Fig. 5b, c and $\mathrm{S} 3 \uparrow$ reveal that the scattering power of a bubble increases significantly as its size increases. Fig. 5d and e indicate that 10 cascaded bubbles with $5 \mu \mathrm{m}$ diameter can reduce the transmission to $60 \%$. The growth and collapse of 
these microbubbles have been investigated in liquid suspensions of $\mathrm{Au}$ or carbon nanoparticles, ${ }^{48,69,70}$ and we believe that the same picture can be applied to graphene dispersions. More vapors will be generated with higher laser powers, resulting in larger microbubbles and stronger OL.

Laser induced ultrasound was used to investigate OL in carbon black and $\mathrm{TiS}_{2}$, and a similar correlation was obtained. ${ }^{32,49,73}$ However, thermal expansion of nanomaterials or solvents, instead of bubbles, was considered to generate the photoacoustic signal, and $\mathrm{OL}$ was attributed to the nonlinear absorption of carbon black or $\mathrm{TiS}_{2} \cdot{ }^{32,49,73}$ Nonlinear scattering of nanomaterials was traditionally referred to their intrinsic nonlinear optical properties. Under a higher laser intensity, the optical refractive index of the suspended nanomaterials increases, resulting in a larger index mismatch with their surrounding media and stronger light scattering. ${ }^{74-77}$ Phenomenologically, the reduced transmission in $Z$-scan appears as a nonlinear effect, but it is misleading to simply call it nonlinear scattering, ${ }^{12-14,17,33,38,44,46,48}$ and the calculation of $\chi^{3}$ based on $Z$-scan alone without knowing the underlying mechanism should be avoided. ${ }^{3,12-14,17,18,22,23,29,33,38,45,48-50,52,53}$

\section{Conclusions}

In conclusion, we have designed and developed a series of experiments to prove that laser induced bubbles are responsible for the observed OL in graphene suspension. The same techniques and mechanism are applicable to other $2 \mathrm{D}$ nanomaterials and even carbon nanotubes. ${ }^{48-51,53}$ Bubble scattering is not a nonlinear optical process, so the mechanism of such OL cannot be simply called nonlinear scattering. An accurate understanding and identification of the mechanism of OL is crucial for the design of effective laser protection media and exploration of optical application of nanomaterials' intrinsic properties. Because of the low laser intensity required to generate microbubbles, it is possible to use graphene to design broadband efficient OL devices.

\section{Author contributions}

Q. Z., Y. Q., F. L., M. A. and S. D. performed optical limiting experiments, C. N., W. Z. and J. H. calculated bubble scattering, F. L., X. Z. and Z. L. synthesized graphene, J. B. and Z. W. designed the experiments. Q. Z. and J. B. wrote the paper. All the authors read the manuscript and provided comments.

\section{Conflicts of interest}

The authors declare no competing financial interest.

\section{Acknowledgements}

Q. H. Zhang acknowledges support from the National Natural Science Foundation of China (No. 61805071, 61605186) and Key Scientific and Technological projects in Henan Province of China (No. 202102310002). J. H. acknowledges support from the U. S. National Science Foundation (ECCS-1809622). J. M. Bao acknowledges support from the Welch Foundation (E-1728) and National Science Foundation (EEC-1530753).

\section{References}

1 L. W. Tutt and T. F. Boggess, Prog. Quantum Electron., 1993, 17, 299-338.

2 Z. Liu, B. Zhang and Y. Chen, Chemistry, 2019, 1, 17-43.

3 Y. Chen, T. Bai, N. Dong, F. Fan, S. Zhang, X. Zhuang, J. Sun, B. Zhang, X. Zhang, J. Wang and W. J. Blau, Prog. Mater. Sci., 2016, 84, 118-157.

4 J. W. You, S. R. Bongu, Q. Bao and N. C. Panoiu, Nanophotonics, 2018, 8, 63-97.

5 Z. Liu, X. Zhang, X. Yan, Y. Chen and J. Tian, Chin. Sci. Bull., 2012, 57, 2971-2982.

6 J. J. Butler, A. S. Bowcock, S. R. Sueoka, S. R. Montgomery, S. R. Flom, E. J. Friebele, B. M. Wright, J. R. Peele, R. G. S. Pong, J. S. Shirk, J. Hu, C. R. Menyuk and T. F. Taunay, Opt. Express, 2013, 21, 20707-20712.

7 F. Bonaccorso, Z. Sun, T. Hasan and A. C. Ferrari, Nat. Photonics, 2010, 4, 611-622.

8 A. K. Geim and K. S. Novoselov, Nat. Mater., 2007, 6, 183-191. 9 J. B. Khurgin, Appl. Phys. Lett., 2014, 104, 161116.

10 J. R. Schaibley, P. Rivera, K. Seyler, T. Karin, J. Yan, D. G. Mandrus, W. Yao, K. M. Fu and X. Xu, CLEO, 2016, 1-2.

11 W. Li, B. Chen, C. Meng, W. Fang, Y. Xiao, X. Li, Z. Hu, Y. Xu, L. Tong, H. Wang, W. Liu, J. Bao and Y. R. Shen, Nano Lett., 2014, 14, 955-959.

12 L. Yan, Y. Xiong, J. Si, X. Sun, W. Yi and X. Hou, Opt. Express, 2014, 22, 31836-31841.

13 J. Wang, Y. Hernandez, M. Lotya, J. N. Coleman and W. J. Blau, Adv. Mater., 2009, 21, 2430-2435.

14 X. Cheng, N. Dong, B. Li, X. Zhang, S. Zhang, J. Jiao, W. J. Blau, L. Zhang and J. Wang, Opt. Express, 2013, 21, 16486-16493.

15 A. Benoy, K. Adarsh, S. S. Siva Sankara, P. Reji and R. Sundara, J. Mater. Chem. C, 2013, 1, 2773-2780.

16 L. Cao, S. Sahu, P. Anilkumar, K. Changyi and S. Ya-Ping, MRS Bull., 2012, 37, 1283-1289.

17 M. Feng, H. Zhan and Y. Chen, Appl. Phys. Lett., 2010, 96, 033107.

18 G. Demetriou, H. T. Bookey, F. Biancalana, E. Abraham, Y. Wang, W. Ji and A. K. Kar, Opt. Express, 2016, 24, 1303313043.

19 Y. Liu, J. Zhou, X. Zhang, Z. Liu, X. Wan, J. Tian, T. Wang and Y. Chen, Carbon, 2009, 47, 3113-3121.

20 G. Lim, Z. Chen, J. Clark, R. G. S. Goh, W. Ng, H. Tan, R. H. Friend, P. K. H. Ho and L. Chua, Nat. Photonics, 2011, 5, 554-560. 
21 Z. Liu, Y. Wang, X. Zhang, Y. Xu, Y. Chen and J. Tian, Appl. Phys. Lett., 2009, 94, 021902.

22 X. Zhang, Z. Liu, X. Li, Q. Ma, X. Chen, J. Tian, Y. Xu and Y. Chen, Opt. Express, 2013, 21, 7511-7520.

23 N. Liaros, K. Iliopoulos, M. M. Stylianakis, E. Koudoumas and S. Couris, Opt. Mater., 2013, 36, 112-117.

24 S. Biswas, A. Kole, C. Tiwary and P. Kumbhakar, RSC Adv., 2016, 6, 10319-10325.

25 N. Liaros, P. Aloukos, A. Kolokithas-Ntoukas, A. Bakandritsos, T. Szabo, R. Zboril and S. Couris, J. Phys. Chem. C, 2013, 117, 6842-6850.

26 X. Zhang, X. Zhao, Z. Liu, S. Shi, W. Zhou, J. Tian, Y. Xu and Y. Chen, J. Opt., 2011, 13, 075202.

27 Y. Yu, L. Yan, M. Yue and H. Xu, R. Soc. Open Sci., 2018, 5, 171436.

28 R. Prizia, C. Conti and N. Ghofraniha, J. Opt. Soc. Am. B, 2019, 36, 19-25.

29 G. Muruganandi, M. Saravanan, G. Vinitha, M. J. Raj and T. S. Girisun, Chem. Phys., 2017, 488, 55-61.

30 F. Ghasemi, S. Razi and K. Madanipour, J. Electron. Mater., 2018, 47, 2871-2879.

31 N. Dong, Y. Li, S. Zhang, X. Zhang and J. Wang, Adv. Opt. Mater., 2017, 5, 1700543.

32 S. J. Varma, J. Kumar, Y. Liu, K. Layne, J. Wu, C. Liang, Y. Nakanishi, A. Aliyan, W. Yang, P. M. Aiayan and J. Thomas, Adv. Opt. Mater., 2017, 5, 1700713.

33 N. Dong, Y. Li, Y. Feng, S. Zhang, X. Zhang, C. Chang, J. Fan, L. Zhang and J. Wang, Sci. Rep., 2015, 5, 14646.

34 M. Zhao, M. Chang, Q. Wang, Z. Zhu, X. Zhai, M. Zirak, A. Z. Moshfegh, Y. Song and H. Zhang, Chem. Commun., 2015, 51, 12262-12265.

35 K. Zhou, M. Zhao, M. Chang, Q. Wang, X. Wu, Y. Song and H. Zhang, Small, 2015, 11, 694-701.

36 H. Long, L. Tao, C. P. Chiu, C. Y. Tang, K. H. Fung, Y. Chai and Y. H. Tsang, Nanotechnology, 2016, 27, 414005.

37 H. Pan, H. Chu, Y. Li, S. Zhao and D. Li, J. Alloys Compd., 2019, 806, 52-57.

38 J. Huang, N. Dong, S. Zhang, Z. Sun, W. Zhang and J. Wang, ACS Photonics, 2017, 4, 3063-3070.

39 F. Zhang, Z. Wu, Z. Wang, D. Wang, S. Wang and X. Xu, RSC Adv., 2016, 6, 20027-20033.

40 X. Zheng, R. Chen, G. Shi, J. Zhang, Z. Xu, X. Cheng and T. Jiang, Opt. Lett., 2015, 40, 3480-3483.

41 X. Jiang, Z. Zeng, S. Li, Z. Guo, H. Zhang, F. Huang and Q. Xu, Materials, 2017, 10, 210.

42 M. M. Ara, H. Akheratdoost and E. Koushki, J. Mol. Liq., 2015, 206, 4-9.

43 M. Zidan, A. Allaf, M. Alsous and A. Allahham, Opt. Laser Technol., 2014, 58, 128-134.

44 L. Vivien, D. Riehl, F. Hache and E. Anglaret, Physica B, 2002, 323, 233-234.

45 S. Husaini, J. E. Slagle, J. M. Murray, S. Guha, L. P. Gonzalez and R. G. Bedford, Appl. Phys. Lett., 2013, 102, 191112.

46 J. Wang and W. J. Blau, J. Phys. Chem. C, 2008, 112, 22982303.
47 J. Wang, D. Fruchtl, Z. Sun, J. N. Coleman and W. J. Blau, J. Phys. Chem. C, 2010, 114, 6148-6156.

48 I. M. Belousova, N. G. Mironova, A. G. Scobelev and M. S. Yur'ev, Opt. Commun., 2004, 235, 445-452.

49 I. M. Kislyakov and C. S. Yelleswarapu, Appl. Phys. Lett., 2013, 103, 151104.

50 M. N. Karen and P. W. Diane, J. Opt. Soc. Am. B, 1995, 12, 1228-1237.

51 I. M. Belousova, N. G. Mironova and M. S. C. Yur'ev, Opt. Spectrosc., 2003, 94, 86-91.

52 H. Zhang, S. Virally, Q. Bao, L. K. Ping, S. Massar, N. Godbout and P. Kockaert, Opt. Lett., 2012, 37, 18561858.

53 R. Y. Krivenkov, T. N. Mogileva, K. G. Mikheev, A. V. Okotrub and G. M. Mikheev, J. Phys. Chem. C, 2018, 122, 16339-16345.

54 K. Parvez, Z. Wu, R. Li, X. Liu, R. Graf, X. Feng and K. Miillen, J. Am. Chem. Soc., 2014, 136, 6083-6091.

55 F. Lin, G. Yang, C. Niu, Y. Wang, Z. Zhu, H. Luo, C. Dai, D. Mayerich, Y. Hu, J. Hu, X. Zhou, Z. Liu, Z. Wang and J. Bao, Adv. Funct. Mater., 2018, 28, 1805255.

56 F. Lin, Z. Zhu, X. Zhou, W. Qiu, C. Niu, J. Hu, D. Keshab, Y. Wang, Z. Zhao, Z. Ren, L. Dimitri, Z. Liu, Z. Wang and J. Bao, Adv. Mater., 2017, 29, 1604453.

57 Y. Wang, Q. Zhang, Z. Zhu, F. Lin, J. Deng, G. Ku, S. Dong, S. Song, M. K. Alam, D. Liu, Z. Wang and J. Bao, Sci. Adv., 2018, 3, e1700555.

58 S. Yue, F. Lin, Q. Zhang, N. Epie, S. Dong, X. Shan, D. Liu, W. Chu, Z. Wang and J. Bao, Proc. Natl. Acad. Sci. U. S. A., 2019, 116, 6580-6585.

59 O. E. Olarte, J. Andilla, E. J. Gualda and P. Loza-Alvarez, Adv. Opt. Photonics, 2018, 10, 111-179.

60 X. Wang, R. S. Witte and H. Xin, Appl. Phys. Lett., 2016, 108, 143104.

61 A. Vogel, S. Busch and U. Parlitz, J. Acoust. Soc. Am., 1996, 100, 148-165.

62 M. G. Gonzalez, X. Liu, R. Niessner and C. Haisch, Appl. Phys. Lett., 2010, 96, 174104.

63 I. Calizo, A. A. Balandin, W. Bao, F. Miao and C. N. Lau, Nano Lett., 2007, 7, 2645-2649.

64 L. A. Openov and A. I. Podlivaev, Phys. Solid State, 2016, 58, 847-852.

65 S. S. Harilal, R. C. Lssac, C. V. Bindhu, V. P. N. Nampoori and C. P. G. Vallabhan, J. Phys. D: Appl. Phys., 1997, 30, 1703-1709.

66 S. Zhang, X. Wang, M. He, Y. Jiang, B. Zhang, W. Huang and B. Huang, Spectrochim. Acta, Part B, 2014, 97, 13-33.

67 L. Lin, X. Peng, Z. Mao, W. Li, M. N. Yogeesh, B. B. Rajeeva, E. P. Perillo, A. K. Dunn, D. Akinwande and Y. Zheng, Nano Lett., 2015, 16, 701-708.

68 A. O. Govorov and R. H. H. Richardson, Nano Today, 2007, 2, 30-38.

69 E. Lukianova-hleb, Y. Hu, L. Latterini, L. Tarpani, S. Lee, R. A. Drezek, J. H. Hafner and D. O. Lapotko, ACS Nano, 2010, 4, 2109-2123. 
70 M. G. Gonzalez, X. Liu, R. Niessner and C. Haisch, Appl. Phys. Lett., 2010, 96, 174104.

71 Y. Wang, Y. Tang, P. Cheng, X. Zhou, Z. Zhu, Z. Liu, D. Liu, Z. Wang and J. Bao, Nanoscale, 2017, 9, 3547-3554.

72 J. Wang, D. Fruchtl, W. J. Blau, O. J. Wang, D. Fruchtl and W. J. Blau, Opt. Commun., 2010, 283, 464-468.

73 P. Chantharasupawong, R. Philip and J. Thomas, Appl. Phys. Lett., 2013, 102, 041116.
74 V. Joudrier, P. Bourdon, F. Hache and C. Flytzanis, Appl. Phys. B, 1998, 67, 627-632.

75 R. W. Terhune, P. D. Maker and C. M. Savage, Phys. Rev. Lett., 1965, 14, 681-684.

76 N. C. Kothari and C. Flytzanis, Opt. Lett., 1987, 12, 492494.

77 R. Sylvie and G. Grazia, Annu. Rev. Phys. Chem., 2012, 63, 353-378. 